\title{
STUDY OF THE LEVELS OF AGGRESSION OF STUDENTS ENGAGED IN JUDO, BASKETBALL, FITNESS, AND TENNIS
}

\author{
A. Yaneva*, E. Stoyanova, V. Lukanova, B. Mitreva, E. Yordanov, T. Gavrailova \\ Department of Sport, Individual Sports and Recreation, Sofia University “St. Kliment Ohridski”, \\ Sofia, Bulgaria
}

\begin{abstract}
This article presents a study of mental resilience, stability (emotional intelligence), and in particular the levels of aggressive response, according to the practices of judo, fitness, basketball, and tennis by students at Sofia University. The levels of aggression as an indicator of students' ability to manage, influence and control their emotions, attitudes, behaviours and the mental and volitional state of the individual were examined with the questionnaire of Bues\&Durke. The study aims to determine, through the levels of aggressive reaction and depression, what is the impact of the sports of judo, fitness, basketball, and tennis practiced at the University of Sofia for the students' mental stability, stability (emotional intelligence). The object of study is the level of physical aggression of students practicing these sports. The subject of the study is the levels of mental resilience of students practicing judo, fitness, tennis, and basketball, broken down by gender, faculty, and age. As a result of the study, it can be summarized that physical aggression can and should be corrected. Family is the main factor that educates the individual and sets his or her direction of development, but sports at the University can correct and compensate for family gaps.
\end{abstract}

Key words: aggressive behaviour, sport, Sofia University

\section{INTRODUCTION}

The dynamics of time are increasingly leaving its mark on people. Homophobic, political, economic and social reforms, aggressive cultural and communicative models, the rapid development of information technology and technology are factors that negatively affect the psyche of the individual. This not only disrupts the cultural-communicative exchange but puts cultural-communicative barriers. The inability of the individual to exist fully and communicate effectively leads to limited opportunities for social realization.

The educational model is an indicator of the value of society. Sport is a fundamental tool for the formation of the high value of the

\footnotetext{
*Correspondence to: Anzhelina Georgieva Yaneva, Department of Sport, Individual sports and recreation, Sofia University "St. Kliment

Ohridski”, Sofia, Bulgaria, 1504, bul. "Tsar

Osvoboditel”15, E-mail: anji@abv.bg, Phone: $+359888434880$
}

individual. It not only activates the vital positive energy of a person but creates conditions for building a strong, sustainable, disciplined character, motivated, mobilized, purposeful person.

The pursuit of social recognition and social assessment is reflected in sportsmanship (fair play) behavior of the individual. Sports education and physical activity are factors of socio-cultural significance and are related to both physical and mental health and stability of the individual (1).

Maintaining good health, the formation of a physically well-developed personality stimulates work and mental performance and affects the overall moral and ethical education. Practicing sports benefits not only physical development but above all emotional, moral, and intellectual growth. During a sports game, emotions, passions, inner potential, and a whole palette of personal characteristics are unlocked, which would not be realized if there 
was no sports provocation - the desire to win, to succeed, to express oneself. No athlete starts with the attitude of loss. The feeling of victory, above all over oneself, on the one hand, forms self-esteem, satisfaction, good self-confidence, calmness, inner harmony, increases motivation and mood, and on the other hand, reduces stress and anxiety.

Neglecting sports is a kind of denial of life, as it creates conditions for the development of negative trends. The worldview of the nonathlete is distorted, limited, filled with delusions - consciously, diligently, and systematically presented by the media and communication. Getting out of this state or realizing it leads to a painful experience, accompanied by feelings of inferiority, complexes, etc., which in combination with the overexposure of negative culturalcommunicative models and alienation (lack of empathy, love, compassion, mercy, etc.) demotivate, demobilize and stimulate - apathy, depression, trigger deviant behavior, aggression, etc.

The individual's desire to compensate for existing deficits pushes him to behavior that is an indicator of his direction of development (constructive or destructive). Aggressive behavior is one form of destructive choice. Methods (forceful, intrusive, and aggressive) and means (unethical, immoral, and unaesthetic) are the results of socio-cultural, communicative, and educational models.

Aggressive behavior could be classified as criminal, as the aggressor with impunity commits an act of violence - physical, mental - emotional, moral, etc. on a defenseless victim.

The topic of aggression and depression is very relevant, especially today when there is a lack of spirituality, and aggression is embedded in the behavior of adolescents (2). Unfortunately, for most people, aggression has also become a way of communication, but for students at Sofia University, where the most intelligent young people study, it should not be at a "high level". The development of emotional intelligence through sports also helps reduce aggression (3) as well as to some extent depression.

To take preventive measures so that aggressive behavior does not escalate into actual criminal behavior, it is necessary to change the attitude towards sports activities. Sport should be a way of life!

In the field of higher education there is a reorientation of the goals and objectives of sports activities. There is a transition from a system that is oriented only to the formation of motor skills and vital motor skills and habits, to a system that provides knowledge about the human body, to maintain and strengthen health, a system that develops the need for a healthy lifestyle and physical improvement (4). The process of education in universities in the discipline of sport is a complex scientifictheoretical and practical-applied pedagogical problem, which implies a motivated desire of students for active and full participation in it. Both sides of this process play a crucial role in the success - the pedagogical function of the teacher and the students learning activities and his motivation. The optimization of the educational process in physical education has a theoretical-methodological and applied nature, requiring periodic updating of curricula and research of students' interest (5).

The opportunity for the individual to improve not only his physical qualities, his mental resilience, but also to re-evaluate moral values is a challenge that provokes scientific research. In this regard, a study was conducted within a project at Sofia University.

The aim of this project is, by taking into account the levels of aggressive reaction and depression, to determine the impact of the sports judo, fitness, basketball, and tennis, practiced at Sofia University for mental resilience, stability (emotional intelligence) of students.

The levels of aggression and depression are an indicator of the students' ability to manage, influence, and control their emotions, attitudes, behavior, as well as the mental and volitional state of the individual. In modern society, the learning and information overload of students, limited physical activity, lack of sufficient movement in human life have an extremely adverse effect on their health, physical development, and capacity (6).

The definition of sports is following some criteria, such as type of sport - different distance, collective (team), martial arts and individual:

- judo - martial arts, close contact, a tackle for winning; 
- fitness - sports with bodybuilding equipment, without an opponent or partner, no contact with an opponent;

- basketball - a sports game with close distance and contact between partners and opponents, to win;

- tennis - a sports game with a large distance between opponents to win.

\section{METHODS}

This article deals only with the scale of "physical aggression". Other types of aggression will be published in separate articles.

The type and level of the aggressive reaction were studied with the questionnaire of A. Buss and A. Durke (7). It was published in 1957 and is considered one of the most reliable methods for checking the level of aggression. It is designed for ages over 14 years.

The questionnaire includes 75 questions divided into 8 scales. Answer with "yes" and "no" (7).

In this article, the study considers only the scale "physical aggression", which includes questions with a key: $+1,-9,-17,+25,+33,+$ $41,+48,+55,+62,+68$.

\section{Lie (social desirability)}

The questions from the "Lie" scale are interpreted as follows: when they are in the given scale, the answer "NO" is considered a manifestation of aggression. When the answer is "YES", aggression is excluded, but the answer is reported in the scale for lying. The key is as follows: $+9,+11,+17,+26,+35,+$ $36,+39,+49,+65,+66,+69,+70,+74,+$ 75.

When the sum of the positive answers on the scale exceeds $50 \%$, it is considered that there is an aggression on this scale. With 8 or more answers on the "Lie" scale, the result is invalid. The methodology of scientific research includes a system of methods and organization of research with the necessary tools, methodological sequence, systematization, and analysis of the research data.

The object of study is the level of physical aggression of students practicing judo, fitness, tennis, and basketball.

The subject of the study is the levels of mental resilience of students practicing the sports of judo, fitness, tennis, and basketball, distributed by gender, faculty, and age.

The study presents 4 types of sports disciplines practiced at Sofia University by students.

The subject (contingent) of research is all students involved in the sports of judo, fitness, tennis, and basketball, divided by gender, faculty, and age.

The surveyed students (133) were aged 19 to 23 years. Students who participate in judo, fitness, tennis, and basketball, divided by gender, faculty, and age, are included, including students who also participate in the representative teams in the sport at Sofia University.

The first phase of the study was conducted from 05.09.2019 to 11.09.2019 - during the summer training and sports practice of students at the University.

\section{RESULTS}

Table 1 and Figure 1 present the results of the aggressive "physical aggression" reaction in sports.

From the reliable results (the other results fall into the column unreliable and not subject to analysis) it is evident that a high level of physical aggression is shown mostly by students who play basketball - 29,20\%, and the lowest are the levels of "physical aggression" in students who practice judo $-7,70 \%$. This fact is not accidental, as the idea of a meaningful life in the Eastern "culture of the road" (expressed in the judo tradition) is opposed to the Western reading of the sport - "culture of achievement" (expressed in a basketball game) (3).

Table 1. Distribution of the aggressive reaction "physical aggression" by sports

\begin{tabular}{|c|c|c|c|c|c|c|}
\hline \multirow{2}{*}{ Reliability } & \multirow{2}{*}{$\begin{array}{l}\text { Level of } \\
\text { aggression }\end{array}$} & \multicolumn{4}{|l|}{ sport } & \multirow{2}{*}{ Total } \\
\hline & & judo & fitness & basketball & tennis & \\
\hline \multirow{4}{*}{ Reliable result } & low & $7,70 \%$ & $11,50 \%$ & & & $5,60 \%$ \\
\hline & weak & $73,10 \%$ & $34,60 \%$ & $25,00 \%$ & $38,50 \%$ & $43,80 \%$ \\
\hline & average & $19,20 \%$ & $38,50 \%$ & $45,80 \%$ & $46,20 \%$ & $36,00 \%$ \\
\hline & high & & $15,40 \%$ & $29,20 \%$ & $15,40 \%$ & $14,60 \%$ \\
\hline \multirow{3}{*}{ Unreliable result } & low & $33,30 \%$ & $28,60 \%$ & $13,30 \%$ & $12,50 \%$ & $20,90 \%$ \\
\hline & weak & $33,30 \%$ & $71,40 \%$ & $20,00 \%$ & $25,00 \%$ & $39,50 \%$ \\
\hline & average & $33,30 \%$ & & $53,30 \%$ & $50,00 \%$ & $32,60 \%$ \\
\hline
\end{tabular}




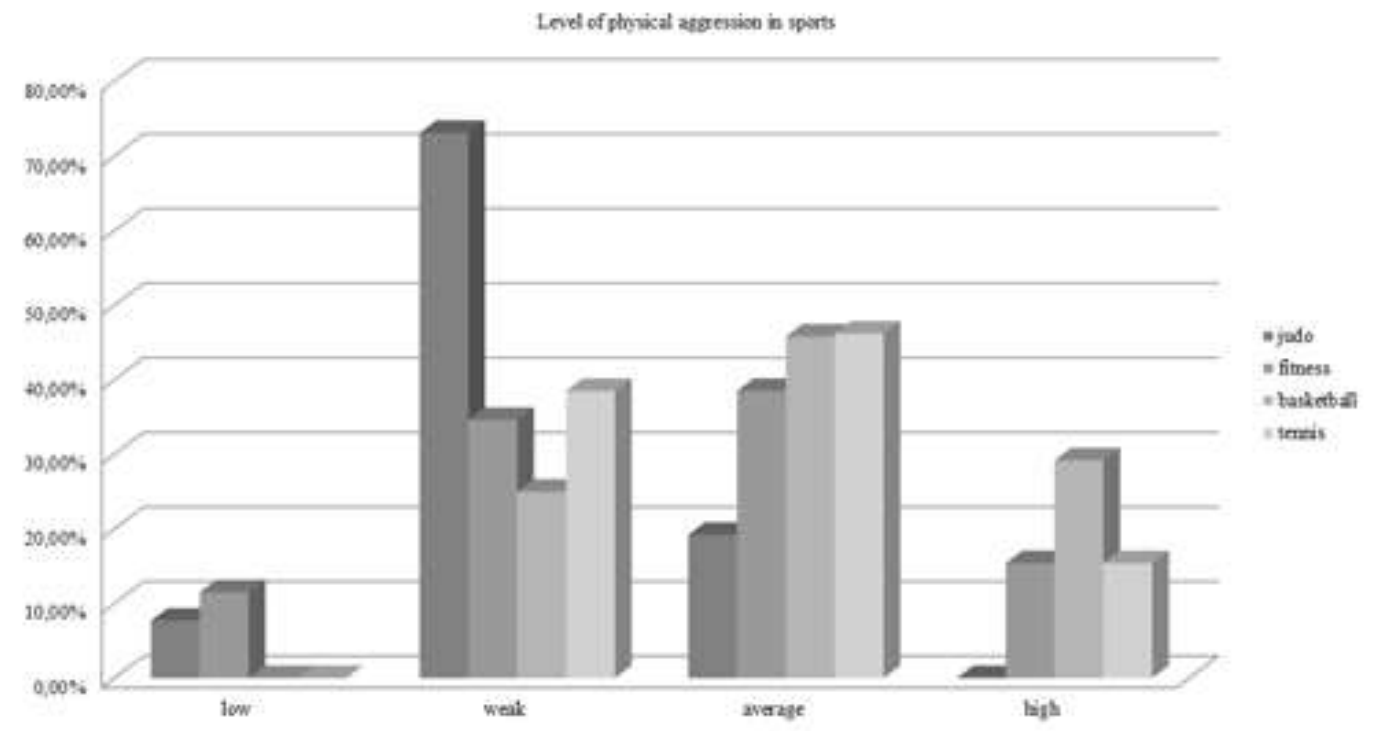

Figure 1. Level of physical aggression in sports

The high percentage of Judo students who show "low physical aggression" is not unnoticed $-73,10 \%$, but we believe that this high percentage should not be worrying, as the trend in this sport is generally the direction of elimination of manifestations of "physical aggression". We believe that this is influenced by the duration of the sport, not the occasional visits, but this has yet to be proven.

From the unreliability of the results can also be concluded, namely that $53,30 \%$ of students who play basketball and $50,00 \%$ of students who practice tennis try to cover up the manifestations of "average level of physical aggression", which is why they give contradictory answers, and hence the result is unreliable.

Impressive is the number of students in sports Tennis (46,20\%), Basketball (45,80\%), Fitness
(38,50\%), who show "average level of physical aggression". In general, the trend in these sports is minimal change, i.e. an average percentage is maintained, decreases, but is not eliminated.

Figure 2 shows the overall results of the "physical aggression" of the surveyed students. It is evident that "low level of physical aggression" is shown by only $5,60 \%$ of the surveyed students, $43,80 \%$ show "low physical aggression", $36,00 \%$ - "medium level of physical aggression", and 14,60\% - "high level of physical aggression". What is reassuring is that the percentage of students who show a "high level of physical aggression" is not very high, although they exist and exist in an environment where an aggressive approach is a way of life.

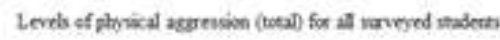

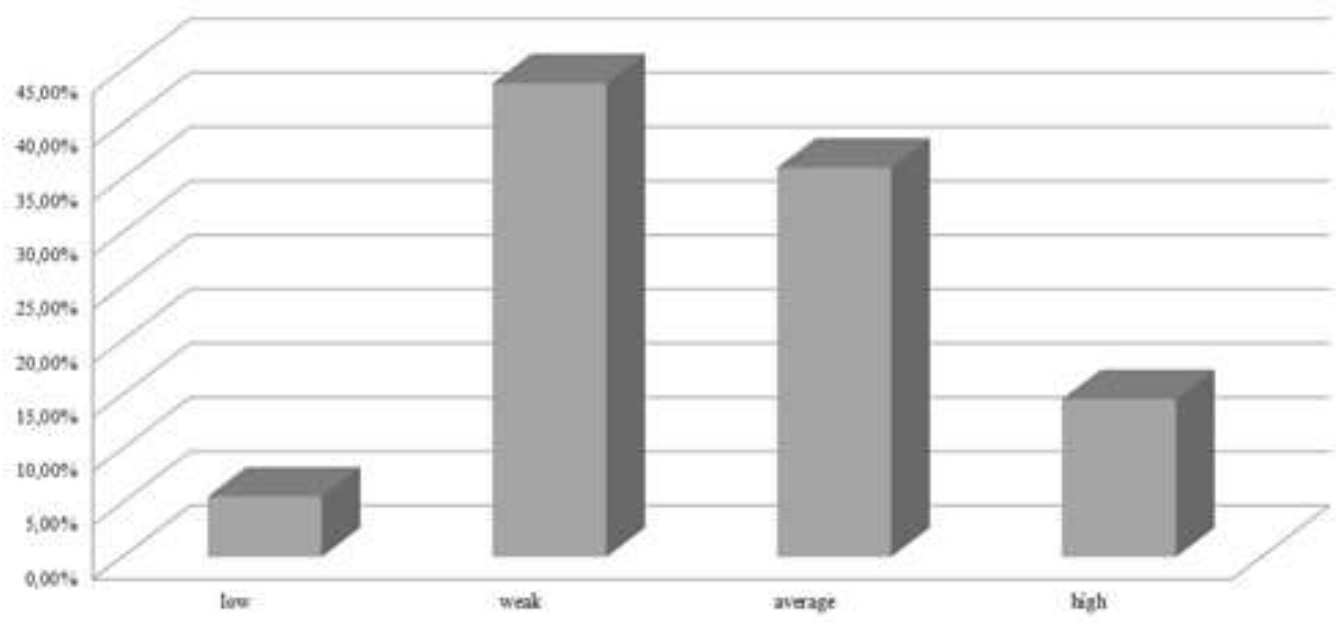

Figure 2. Levels of physical aggression (total) for all surveyed students 
Table 2 and Figure 3 show the levels of physical aggression, broken down by gender.

The results show (this part, which is considered reliable), that more women $(57,30 \%)$ than men $(42.70 \%)$ were studied. We must also consider the fact that the fitness subjects studied in sports are only women, which is an omission on our part and in the future stage men should also be covered.
In both sexes, the tendency is to show a "medium level of physical aggression" $50.00 \%$, but all men who show "high" and "very high" levels of physical aggression try to hide this fact, which they show contradictory answers and unreliable results. This suggests that men show more aggression, which they try to cover up.

Table 2. Physical aggression, distributed by gender

\begin{tabular}{|l|l|l|l|l|l|l|l|}
\hline \multirow{2}{*}{ Reliability } & \multirow{2}{*}{ gender } & \multicolumn{2}{l}{ Level of aggression } \\
\cline { 3 - 8 } & & low & weak & average & high & very high & Total \\
\hline \multirow{2}{*}{ Reliable result } & male & $20,00 \%$ & $35,90 \%$ & $50,00 \%$ & $53,80 \%$ & & $42,70 \%$ \\
\cline { 2 - 8 } & female & $80,00 \%$ & $64,10 \%$ & $50,00 \%$ & $46,20 \%$ & & $57,30 \%$ \\
\hline \multirow{2}{*}{ Unreliable result } & male & $55,60 \%$ & $29,40 \%$ & $85,70 \%$ & $100,00 \%$ & $100,00 \%$ & $58,10 \%$ \\
\cline { 2 - 8 } & female & $44,40 \%$ & $70,60 \%$ & $14,30 \%$ & & & $41,90 \%$ \\
\hline
\end{tabular}

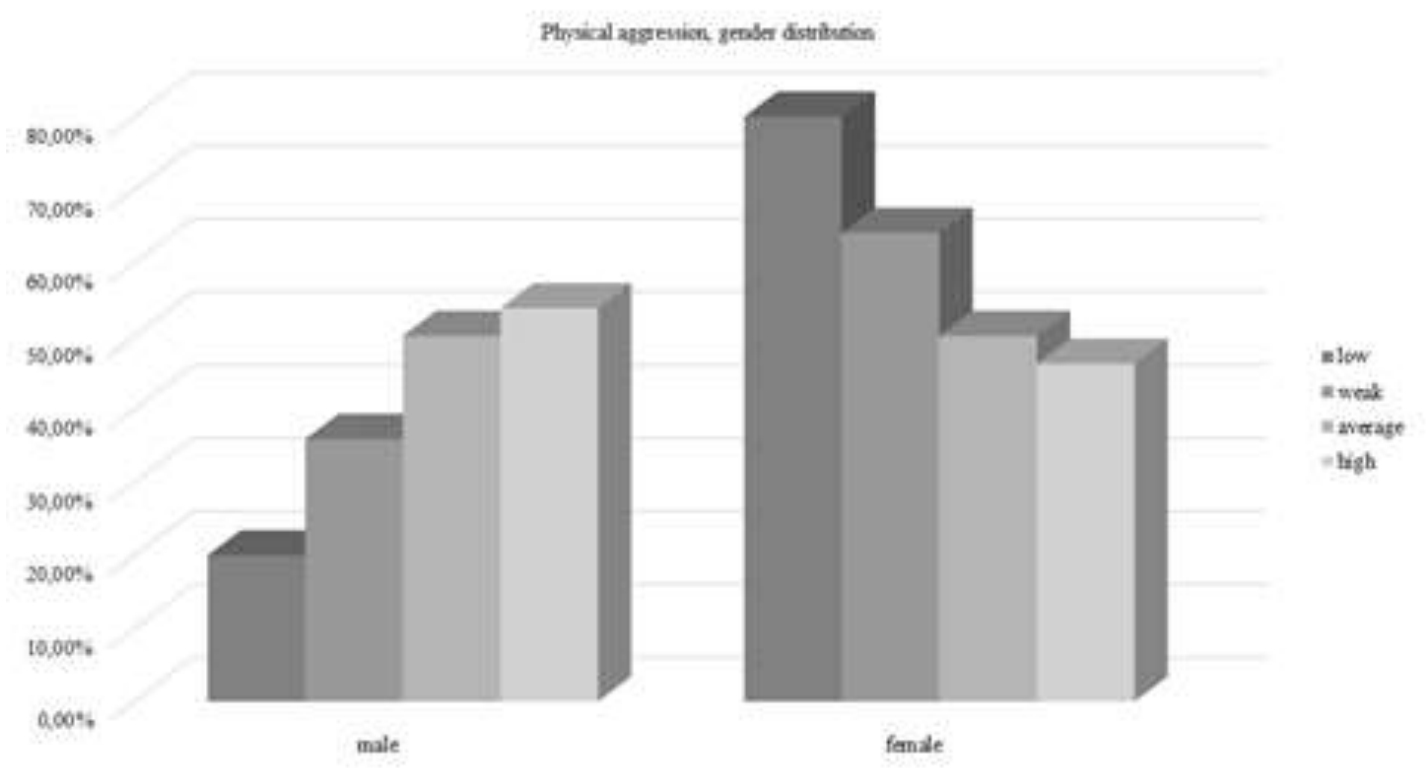

Figure 3. Physical aggression, gender distribution

\section{CONCLUSIONS}

In conclusion, it can be concluded that physical aggression can and should be corrected and the family is the main factor that educates the individual and sets his directions of development, but sports at the university can correct and compensate for family shortcomings. The strong-minded individual does not cause physical harm, does not hurt the other.

In the next stage of the research, the information about other types of aggression will be synthesized and analyzed, as well as about other sports, including fitness - men.

At this stage, the information obtained enables teachers from the Department of Sports to look for ways to improve not only the quality of education, the work in organizing and carrying out sports activities at the university, but also the formation of balanced personalities.

The scientific idea and the use of the research results will be used to upgrade and attract researchers from other Universities in Bulgaria and abroad to continue the research and expand its scope.

\section{ACKNOWLEDGMENTS}

This article is published with the financial support of project № 80-10-63/10.04.2019, according to Ordinance No. 9 of the State Budget of the Republic of Bulgaria. 


\section{REFERENCES}

1. Prokopov, E., Judo - philosophy, history, structure, essence. University press ,St. Kliment Okhridski“, S., 2005, pp 8, 9, 15, 31.

2. Yordanov, E., S., Yordanov, Factors causing football hooliganism. In: Extraordinary Issue \# 6, Department of Football and Tennis, NSA "V. Levski", S., 2015.

3. Stoyanova, E., Judo-condition for development of emotional intelligence. dis. 2017.

4. Dimitrova, N., Nasiev, Er., Pavlov Hr., Quantitative assessment of physical fitness in elementary school age. In: Challenges and Prospects for Sports Science, NSA
PRESS, Sofia, 2017, pp.197-204.

5. Dyakova, G., Dyakov, T., Angelova, I., Study of the students' interest in the football game, motivation and desire for practicing football. In: Trakia Journal of Sciences, Vol. 15, Suppl. 1, 2017.

6. Yaneva, A., Stoyanova, E., Stage of the study of aggression and depression of students from Sofia university sports judo, basketball, fitness and tennis. In: Modern trends of physical education and sport, University press „St. Kliment Okhridski“, S., 2019, pp 22-25.

7. Ivanov, I., Methods for personality trait research. ed. Axios, Shumen, 1999.

8. Siek, S., Wybrane metody badania osobowosci. W., 1983. 